\title{
A randomized clinical trial using cyclopentolate and tropicamide to compare cycloplegic refraction in Chinese young adults with dark irises
}

Ruxia Pei ${ }^{1}$, Zhuzhu Liu', Hua Rong ${ }^{1}$, Liqiong Zhao ${ }^{1}$, Bei Du', Na Jin ${ }^{1}$, Hongmei Zhang ${ }^{1}$, Biying Wang ${ }^{1}$, Yi Pang ${ }^{2^{*}}$ and Ruihua Wei ${ }^{1^{*}}$ (D)

\begin{abstract}
Background: To evaluate the necessity of cycloplegia for epidemiological studies of refraction in Chinese young adults (aged 17-22 years) with dark irises, and to compare the cycloplegic effects of 1\% cyclopentolate and 0.5\% tropicamide in them.

Methods: A total of 300 young adults (108 males and 192 females) aged 17 to 22 years (mean 19.03 \pm 1.01 ) were recruited from Tianjin Medical University from November 2019 to January 2020. Participants were randomly divided into two groups. In the cyclopentolate group, two drops of $1 \%$ cyclopentolate eye drop were administrated (one drop every $5 \mathrm{~min}$ ), followed by autorefraction and subjective refraction 30 to $45 \mathrm{~min}$ later. In the tropicamide group, four drops of $1 \%$ Mydrin P (Tropicamide $0.5 \%$, phenylephrine $\mathrm{HCl} 0.5 \%$ ) eye drop were given (one drop every 5 $\mathrm{min})$, followed by autorefraction and subjective refraction 20 to $30 \mathrm{~min}$ later. The participants and the examiners were masked to the medication. Distance visual acuity, intraocular pressure (IOP), non-cycloplegic and cycloplegic autorefraction (Topcon KR-800, Topcon Co. Tokyo, Japan), non-cycloplegic and cycloplegic subjective refraction and ocular biometry (Lenstar LS-900) were performed.

Results: The values of spherical equivalent (SE) and sphere component were significantly different before and after cycloplegia in the cyclopentolate group and the tropicamide group $(p<0.05)$. The mean difference between noncycloplegic and cycloplegic autorefraction SE was $0.39 \mathrm{D}( \pm 0.66 \mathrm{D})$ in the cyclopentolate group and $0.39 \mathrm{D}( \pm$ $0.34 \mathrm{D})$ in the tropicamide group. There was no significant difference in the change of SE and sphere component after cycloplegia between the cyclopentolate group and the tropicamide group ( $p>0.05$ ). In each group, no significant difference was found between autorefraction and subjective refraction after cycloplegia $(p>0.05)$. We also found that more positive or less negative cycloplegic refraction was associated with the higher difference in SE in each group.
\end{abstract}

\footnotetext{
* Correspondence: YPang@ico.edu; rwei@tmu.edu.cn

${ }^{2}$ Illinois College of Optometry, 3241 S, Michigan Ave, Chicago, IL 60616, USA 'Tianjin Key Laboratory of Retinal Functions and Diseases, Tianjin Branch of National Clinical Research Center for Ocular Disease, Eye Institute and School of Optometry, Tianjin Medical University Eye Hospital, 251 Fukang Road, Nankai District, Tianjin, China
}

(c) The Author(s). 2021 Open Access This article is licensed under a Creative Commons Attribution 4.0 International License, which permits use, sharing, adaptation, distribution and reproduction in any medium or format, as long as you give appropriate credit to the original author(s) and the source, provide a link to the Creative Commons licence, and indicate if changes were made. The images or other third party material in this article are included in the article's Creative Commons licence, unless indicated otherwise in a credit line to the material. If material is not included in the article's Creative Commons licence and your intended use is not permitted by statutory regulation or exceeds the permitted use, you will need to obtain permission directly from the copyright holder. To view a copy of this licence, visit http://creativecommons.org/licenses/by/4.0/ The Creative Commons Public Domain Dedication waiver (http://creativecommons.org/publicdomain/zero/1.0/) applies to the data made available in this article, unless otherwise stated in a credit line to the data. 
Conclusions: Cycloplegic refractions were generally more positive or less negative than non-cycloplegic refractions. It is necessary to perform cycloplegia for Chinese young adults with dark irises to obtain accurate refractive errors. We suggest that cycloplegic autorefraction using tropicamide may be considered as a reliable method for epidemiological studies of refraction in Chinese young adults with dark irises.

Trial registration: The study was registered on September 7, 2019 (Registration number: ChiCTR1900025774).

Keywords: Chinese young adult, Tropicamide, Cyclopentolate, Autorefraction, Subjective refraction

\section{Background}

Cycloplegic refraction using cycloplegic agents is an effective way to control accommodation [1-3]. Adequate cycloplegia is of great importance to obtain accurate refractive errors [2, 4-7]. Cycloplegic refraction is the gold standard method for epidemiological studies in children and adolescents $[4,8]$, but the use of cycloplegia in young adults is still controversial. Some studies have been conducted to determine the necessity of cycloplegia and different results have been reported in young adults [9-13]. Yun-Yun Sun et al. suggested that cycloplegia is essential and necessary for Chinese young adults (mean aged $20.2 \pm 1.5$ years) in epidemiological studies [9]. The Tehran Eye study [12] found that cycloplegia is required for epidemiological studies, up to the age of 50. On the contrary, Sanfilippo et al [13] and Krantz et al [11] suggested that it is not necessary to perform cycloplegia in young adults for epidemiological studies of refraction.

The three most commonly used cycloplegic agents include atropine, tropicamide and cyclopentolate [14]. The ideal cycloplegic agent characterized by rapid onset, short duration of action, complete cycloplegia, and absence of side effect [15]. Atropine is the gold standard for its cycloplegic effect, but the onset is very slow and recovery time is always as long as 15 to 20 days [16]. Therefore, it is not routinely used as a diagnostic agent in adults. Cyclopentolate is a synthetic antimuscarinic cycloplegic agent which is widely accepted as the cycloplegic agent in children and has been showed as effective as atropine at obtaining cycloplegia [17]. For individuals with dark irises, cyclopentolate is characterized by an onset of quick action (30-45 min), a relatively short duration of action (24-48 h) and few side effects [18]. Tropicamide is a synthetic analog of tropic acid which is another choice of cycloplegic agent, also known as a rapid and safe agent for cycloplegic refraction [19]. Compared with cyclopentolate, tropicamide is more acceptable in patients $[20,21]$ for its profiles of faster onset (20-30 min) and recovery $(6-7 \mathrm{~h})$.

For young adults, little research has been done to compare the cycloplegic effects of cyclopentolate and tropicamide [20-22]. Gettes et al [22] and Hofmeister et al [21] suggested that cyclopentolate and tropicamide may be equally effective in refractive measurements in young adults. One study of 25 Black young adults with dark irises found that the cycloplegic effect of cyclopentolate was stronger than tropicamide [20]. It has been reported that there is a delay in onset and a decrease in magnitude of cycloplegic effect with increased iris pigmentation in eyes caused by pigment binding of the cycloplegic agents [23, 24]. Manny et al [18] found it took longer for adults with dark irises to reach the maximum cycloplegia effect. However, there is a lack of comparable study on Chinese young adults (aged 17-22 years) with dark irises.

The purpose of this prospective randomized controlled study was to evaluate the necessity of cycloplegia in Chinese young adults (aged 17-22 years) with dark irises, and to compare the cycloplegic effects of cyclopentolate and tropicamide in them.

\section{Method \\ Subjects}

Young Chinese adults aged 17 to 22 years with dark irises were recruited from Tianjin Medical University from November 2019 to January 2020. Written informed consent was obtained from each participant before the data collection. This study was approved by Tianjin Medical University Eye Hospital ethics committee and the conduct of the study adhered to the tenets of the Declaration of Helsinki.

Participants with strabismus, amblyopia, nystagmus, glaucoma, contact lens, a history of ocular surgery, trauma or other ophthalmic diseases were excluded from the study.

\section{Procedures}

Considering $80 \%$ power and a 5\% confidence level and allowing for $10 \%$ loss to follow-up, a sample size of 150 young adults in each of the two intervention arms was sufficient. The randomization number was generated automatically by the manager of the Clinical Trial Coordination Centre by means of a computerized randomnumber generator. The intervention group was concealed in numbered, opaque envelopes which were contained in a box. Each young adult selected one envelope 
and gave it to the nurse, who opened the envelope and administered the appropriate cycloplegic agent at that time. Participants were randomly divided into two groups according to the numbers. The cyclopentolate group performed a cyclopentolate regimen with the administration of one drop of $0.4 \%$ oxybuprocaine hydrochloride followed by two drops of $1 \%$ cyclopentolate hydrochloride (Alcon) at 5-min intervals. Cycloplegic autorefraction and subjective refraction were performed between $30 \mathrm{~min}$ and $45 \mathrm{~min}$ after the last instillation of cyclopentolate, when the pupillary light reflex was eliminated. The tropicamide group performed a tropicamide regimen with the administration of one drop of $0.4 \%$ oxybuprocaine hydrochloride followed by four drops of Mydrin P (Tropicamide 0.5\%, phenylephrine $\mathrm{HCl} 0.5 \%$; Santen Pharmaceutical, Shiga, Japan) at 5-min intervals. Cycloplegic autorefraction and subjective refraction were performed between $20 \mathrm{~min}$ and $30 \mathrm{~min}$ after the last instillation of Mydrin P, when the pupillary light reflex was eliminated. To prevent discomfort in participants, a drop of oxybuprocaine eye drops, had been used before administration of cycloplegic agent. The cycloplegic agent was carefully instilled into the conjunctival sac in order to avoid irritating tearing, which may affect the cycloplegic function [25]. The examiners and participants were masked which cycloplegic agent was applied.

\section{Examinations}

All participants underwent a comprehensive standard examination at the optometry laboratory in Tianjin Medical University. Distance visual acuity (logMAR chart), intraocular pressure (non-contact tonometry, Topcon CT-1), noncycloplegic and cycloplegic autorefraction (Topcon KR-800), non-cycloplegic and cycloplegic subjective refraction and ocular biometry (Lenstar LS-900) were performed. All ophthalmologic examinations were conducted by one ophthalmologist, six optometrists and two nurses. A training course was conducted to ensure all examinations would be performed under the same criteria and a comprehensive standard procedure was made for the whole outcome recording during the study. Uncorrected visual acuity (UCVA) and best corrected visual acuity (BCVA) was measured using $\log$ MAR chart with tumbling E. Intraocular pressure (IOP) before cycloplegia was measured using non-contact tonometry (Topcon CT-1). Autorefraction and subjective refraction were measured by the same optometrists before and after cycloplegia. Subjective refraction was performed based on subjective refinement of the autorefractor readings until best-corrected visual acuity was achieved (BCVA).

\section{Definitions}

The noncycloplegic and cycloplegic refraction obtained from the autorefractor and subjective refraction between the two groups were decomposed into three components: sphere (S), cylinder (C) and axis (A). SE was calculated according to using the formula: $\mathrm{SE}=\mathrm{S}+$ $\mathrm{C} / 2$. In this study, young adults were divided into five categories based on cycloplegic SE: low myopia ($3.0 \mathrm{D}<\mathrm{SE} \leq-0.5 \mathrm{D})$, moderate myopia $(-6.0 \mathrm{D}<\mathrm{SE} \leq-$ $3.0 \mathrm{D})$, high myopia $(\mathrm{SE} \leq-6.0 \mathrm{D})$, emmetropia $(-0.5 \mathrm{D}<$ $\mathrm{SE} \leq+0.5 \mathrm{D})$ and hyperopia $(\mathrm{SE}>+0.50 \mathrm{D})$. The hyperopic participants were all categorized in one group because of the low incidence of hyperopia in young adults.

\section{Statistical analysis}

Results from autorefraction and subjective refraction before and after cycloplegia were recorded. As the correlation coefficients of non-cycloplegic refraction and cycloplegic refraction between OD and OS were high, only data from right eyes were used for data analysis. Numeric values were presented as mean \pm standard deviation (SD) or median. Independent-samples $\mathrm{T}$ test, chi-square test and Wilcoxon test were applied to compare basic participants characteristics and differences in refraction (spherical and cylinder components, and SE) after cycloplegia. Pearson's correlation coefficient was used to show the correlation between cycloplegic autorefraction and cycloplegic subjective refraction. Spearman correlation analysis was used to determine the relationship between difference in SE and cycloplegic SE because those measurements were not normally distributed. A two-sided $p$ value less than 0.05 was considered statistically significant. Statistical analysis was performed using a computer package program SPSS 23.0 (IBM Co., Armonk, NY).

\section{Results}

A total of 300 young adults (108 males and 192 females) aged 17 to 22 years (mean $19.03 \pm 1.01 \mathrm{y}$ ) were included in this study. Of the 300 young adults, 150 received cyclopentolate and 150 received tropicamide for cycloplegia. None of them was lost to follow up. No significant differences were observed in age, gender, and noncycloplegic refraction between the cyclopentolate group and the tropicamide group (Table 1).

Tables 2 and 3 show the results of refractions before and after cycloplegia in the cyclopentolate group and the tropicamide group, respectively. The overall distribution of difference in refraction indicated that cycloplegic refractions were more positive or less negative than noncycloplegic refractions. The values of SE and sphere component were significantly different before and after cycloplegia in tropicamide group and cyclopentolate group ( $p<0.05$ for all). Table 4 shows the changes in refraction after cycloplegia in the two groups. No significant differences were found in the changes of SE and sphere component between the cyclopentolate group and the tropicamide group $(p>0.05)$. There was no 
Table 1 Participant's characteristics

\begin{tabular}{|c|c|c|c|}
\hline & Cyclopentolate $(n=150)$ & Tropicamide $(n=150)$ & $p$-value \\
\hline Age (y) & $18.95 \pm 1.05$ & $19.10 \pm 0.98$ & $0.184^{*}$ \\
\hline Sex & & & $0.463^{\hbar 3}$ \\
\hline Male & $57(38.0 \%)$ & $51(34.0 \%)$ & \\
\hline Female & $93(62.0 \%)$ & 99 (66.0\%) & \\
\hline \multicolumn{4}{|l|}{ Mean autorefractive error (D) } \\
\hline Sphere (noncycloplegic) & $-4.01 \pm 2.26$ & $-3.98 \pm 2.61$ & $0.923^{*}$ \\
\hline Cylinder (noncycloplegic) & $-0.77 \pm 0.96(-0.50)$ & $-0.83 \pm 0.77(-0.50)$ & $0.101^{+}$ \\
\hline Spherical equivalent (noncycloplegic) & $-4.39 \pm 2.37$ & $-4.39 \pm 2.70$ & $0.999^{*}$ \\
\hline \multicolumn{4}{|l|}{ Mean subjective refractive error (D) } \\
\hline Sphere (noncycloplegic) & $-4.06 \pm 2.22$ & $-3.97 \pm 2.59$ & $0.744^{*}$ \\
\hline Cylinder (noncycloplegic) & $-0.62 \pm 0.78(-0.50)$ & $-0.71 \pm 0.73(-0.50)$ & $0.053^{+}$ \\
\hline Spherical equivalent (noncycloplegic) & $-4.37 \pm 2.31$ & $-4.33 \pm 2.64$ & $0.877^{*}$ \\
\hline
\end{tabular}

Values are presented as mean \pm standard deviation, median or number (\%)

$D$ diopters

${ }^{*} p$-value by t-test; $p$-value by chi-square test; $+p$-value by Wilcoxon test

significant difference in the cylinder component before and after cycloplegia.

Results of sphere and spherical equivalent values obtained by cycloplegic autorefraction and cycloplegic subjective refraction are listed in Table 5. Mean sphere and spherical equivalent refraction values were of no significant difference between cycloplegic autorefraction and cycloplegic subjective refraction in cyclopentolate group and in tropicamide group. In the cyclopentolate group, the correlation between the two methods was 0.989 for sphere and 0.983 for spherical equivalent values. In the tropicamide group, the correlation between the two methods was 0.993 for sphere and 0.992 for spherical equivalent values.

7Figure 1 shows the distributions of non-cycloplegic and cycloplegic SE. All these differences were statistically significant (all $p<0.05$ ). As shown in Fig. 1 , young adults were divided into different categories by cycloplegic SE and difference in SE before and after cycloplegia were compared among the five categories in both groups. In the cyclopentolate group, the difference in autorefraction $\mathrm{SE}$ after cycloplegia decreased from $1.08 \pm 0.70 \mathrm{D}$ in hyperopia to $0.21 \pm 0.28 \mathrm{D}$ in high myopia. In the tropicamide group, the difference in autorefraction SE after cycloplegia decreased from $1.17 \pm 0.73 \mathrm{D}$ in hyperopia to $0.22 \pm 0.19 \mathrm{D}$ in high myopia. Changes in autorefraction SE after cycloplegia were similar between the cyclopentolate group and the tropicamide group $(0.39 \pm 0.36 \mathrm{D}$ vs $0.39 \pm 0.40 \mathrm{D}, p>$ $0.05)$. Spearman correlation showed a significant positive correlation between difference in SE before and after cycloplegia and cycloplegic refraction in both the cyclopentolate group $(r=0.40, p<0.01)$ and the tropicamide group $(r=0.54, p<0.01)$. The slope of the regression line was 0.059 in the cyclopentolate group and 0.063 in the tropicamide group, which indicated the more hyperopia or less myopia the larger difference in SE.

Figure 2 illustrates the prevalence of refractive errors based on non-cycloplegic (NC) and cycloplegic (C) SE in

Table 2 Non-cycloplegic and cycloplegic refraction in the cyclopentolate group

\begin{tabular}{|c|c|c|c|c|}
\hline & Non-cycloplegic & Cycloplegic & Difference & $p$-value \\
\hline \multicolumn{5}{|l|}{ Autorefraction } \\
\hline Sphere (D) & $-4.01 \pm 2.26$ & $-3.60 \pm 2.38$ & $0.40 \pm 0.34$ & $<0.01^{*}$ \\
\hline Cylinder (D) & $-0.77 \pm 0.96(-0.50)$ & $-0.79 \pm 0.90(-0.50)$ & $-0.02 \pm 0.27(0.00)$ & $0.311^{+}$ \\
\hline Spherical Equivalent (D) & $-4.39 \pm 2.37$ & $-4.00 \pm 2.49$ & $0.39 \pm 0.36$ & $<0.01^{*}$ \\
\hline \multicolumn{5}{|l|}{ Subjective refraction } \\
\hline Sphere (D) & $-4.06 \pm 2.22$ & $-3.67 \pm 2.38$ & $0.39 \pm 0.32$ & $<0.01^{*}$ \\
\hline Cylinder (D) & $-0.62 \pm 0.78(-0.50)$ & $-0.61 \pm 0.74(-0.50)$ & $0.02 \pm 0.29(0.00)$ & $0.446^{+}$ \\
\hline Spherical Equivalent (D) & $-4.37 \pm 2.31$ & $-3.97 \pm 2.50$ & $0.40 \pm 0.35$ & $<0.01^{*}$ \\
\hline
\end{tabular}

Values are presented as mean \pm standard deviation or median ${ }^{*} p$-value by $\mathrm{t}$-test; $+p$-value by Wilcoxon test 
Table 3 Non-cycloplegic and cycloplegic refraction in the tropicamide group

\begin{tabular}{|c|c|c|c|c|}
\hline & Non-cycloplegic & Cycloplegic & Difference & $p$-value \\
\hline \multicolumn{5}{|l|}{ Autorefraction } \\
\hline Sphere (D) & $-3.98 \pm 2.61$ & $-3.58 \pm 2.76$ & $0.40 \pm 0.32$ & $<0.01^{*}$ \\
\hline Cylinder (D) & $-0.83 \pm 0.77(-0.50)$ & $-0.84 \pm 0.78(-0.50)$ & $-0.01 \pm 0.27(0.00)$ & $0.677^{+}$ \\
\hline Spherical equivalent (D) & $-4.39 \pm 2.70$ & $-4.00 \pm 2.86$ & $0.39 \pm 0.34$ & $<0.01^{*}$ \\
\hline \multicolumn{5}{|l|}{ Subjective refraction } \\
\hline Sphere (D) & $-3.97 \pm 2.59$ & $-3.58 \pm 2.78$ & $0.39 \pm 0.34$ & $<0.01^{*}$ \\
\hline Cylinder (D) & $-0.71 \pm 0.73(-0.50)$ & $-0.71 \pm 0.77(-0.50)$ & $0.00 \pm 0.31(0.00)$ & $0.543^{+}$ \\
\hline Spherical equivalent (D) & $-4.33 \pm 2.64$ & $-3.93 \pm 2.87$ & $0.39 \pm 0.38$ & $<0.01^{*}$ \\
\hline
\end{tabular}

Values are presented as mean \pm standard deviation or median

${ }^{*} p$-value by t-test; $+p$-value by Wilcoxon test

both groups. Before cycloplegia, the prevalence of myopia was $0.7 \%$ in the cyclopentolate group and $1.7 \%$ in the tropicamide group. After cycloplegia, the prevalence of myopia was $2.0 \%$ in the cyclopentolate group and $5.1 \%$ in the tropicamide group.

\section{Discussion}

Our results indicated that the values of SE and sphere component were significantly different before and after cycloplegia in both the tropicamide group and the cyclopentolate group. This suggests that it is necessary to perform cycloplegia refraction for Chinese young adults to obtain accurate refractive errors. No significant difference was found between autorefraction and subjective refraction with cycloplegia $(p>0.05)$. The cycloplegic effects of the two cycloplegic agents is comparable to each other. The value of cylinder component before and after cycloplegia was not significantly different in our study.

Our results indicated that cycloplegic refractions were generally more positive or less negative than noncycloplegic refractions in the cyclopentolate group and the tropicamide group. Our results were consistent with the previous studies [10-12, 26]. Mimouni et al [10] reported 700 soldiers aged 18 to 21 years using $1 \%$ cyclopentolate and found the difference in SE was $0.46 \mathrm{D}$ in myopes and $1.30 \mathrm{D}$ in hyperopes. They concluded that it was necessary to perform cycloplegia in this age group (18-21 years). The Tehran Eye study [12] analyzed participants with a wide age range from 5 to 95 years and showed that the mean difference in SE after using 1\% cyclopentolate was around $0.4 \mathrm{D}$ in the $16-20$ age group. In the study of Krantz, they used 1\% tropicamide as cycloplegic agent and showed the difference in SE for participants (aged 22-39 years) was 0.44D [11]. Another study of 7793 healthy young adults (mean aged $20.2 \pm$ 1.5 years) was conducted to compare autorefractions before and after cycloplegia [9]. The difference in SE with a mean of $0.83 \pm 0.81 \mathrm{D}$ (median 0.63D) is larger than our findings [9]. First, the distribution of cycloplegic refractions in population was different between their study and ours. Second, their study was based on a cycloplegic regimen of two drops of $1 \%$ cyclopentolate followed by one drop of $0.5 \%$ tropicamide. Only cyclopentolate or tropicamide was used in our study. Those two factors may explain the different findings.

We also found that more positive or less negative cycloplegic refraction was associated with the higher difference in SE, which was consistent with previous studies in children or young adults $[8,10,12,13]$. Hyperopes showed a larger difference in refraction before and after cycloplegia than myopes $(1.08 \pm 0.70 \mathrm{D}$ vs $0.35 \pm 0.31 \mathrm{D}$ in cyclopentolate group and $1.17 \pm 0.73 \mathrm{D}$ vs $0.32 \pm 0.26 \mathrm{D}$

Table 4 Changes in autorefraction and subjective refraction before and after cycloplegia

\begin{tabular}{|c|c|c|c|}
\hline & Cyclopentolate Group $(n=150)$ & Tropicamide Group $(n=150)$ & $p$-value ${ }^{+}$ \\
\hline \multicolumn{4}{|l|}{ Autorefraction } \\
\hline Sphere change (D) & $0.40 \pm 0.34(0.25)$ & $0.40 \pm 0.32(0.25)$ & 0.903 \\
\hline Cylinder change (D) & $-0.02 \pm 0.27(0.00)$ & $-0.01 \pm 0.27(0.00)$ & 0.650 \\
\hline Spherical equivalent change (D) & $0.39 \pm 0.36(0.38)$ & $0.39 \pm 0.34(0.38)$ & 0.962 \\
\hline \multicolumn{4}{|l|}{ Subjective refraction } \\
\hline Sphere change (D) & $0.39 \pm 0.32(0.25)$ & $0.39 \pm 0.34(0.25)$ & 0.812 \\
\hline Cylinder change (D) & $0.02 \pm 0.29(0.00)$ & $0.00 \pm 0.31(0.00)$ & 0.844 \\
\hline Spherical equivalent change (D) & $0.40 \pm 0.35(0.38)$ & $0.39 \pm 0.38(0.38)$ & 0.526 \\
\hline
\end{tabular}

Values are presented as mean \pm standard deviation(median)

$+p$-value by Wilcoxon test 
Table 5 Mean values by cycloplegic autorefraction and cycloplegic subjective refraction

\begin{tabular}{|c|c|c|c|c|}
\hline & Autorefraction & Subjective refraction & $p$-value* & $r$ \\
\hline \multicolumn{5}{|c|}{ Cyclopentolate Group $(n=150)$} \\
\hline Sphere (D) & $-3.60 \pm 2.38$ & $-3.67 \pm 2.38$ & 0.744 & 0.989 \\
\hline Spherical equivalent (D) & $-4.00 \pm 2.49$ & $-3.97 \pm 2.50$ & 0.475 & 0.983 \\
\hline \multicolumn{5}{|l|}{ Tropicamide Group ( $n=150)$} \\
\hline Sphere (D) & $-3.58 \pm 2.76$ & $-3.58 \pm 2.78$ & 0.866 & 0.993 \\
\hline Spherical equivalent (D) & $-4.00 \pm 2.86$ & $-3.94 \pm 2.87$ & 0.532 & 0.992 \\
\hline
\end{tabular}

Values are presented as mean \pm standard deviation

${ }^{*} p$-value by t-test. $r$ by Pearson correlation analysis

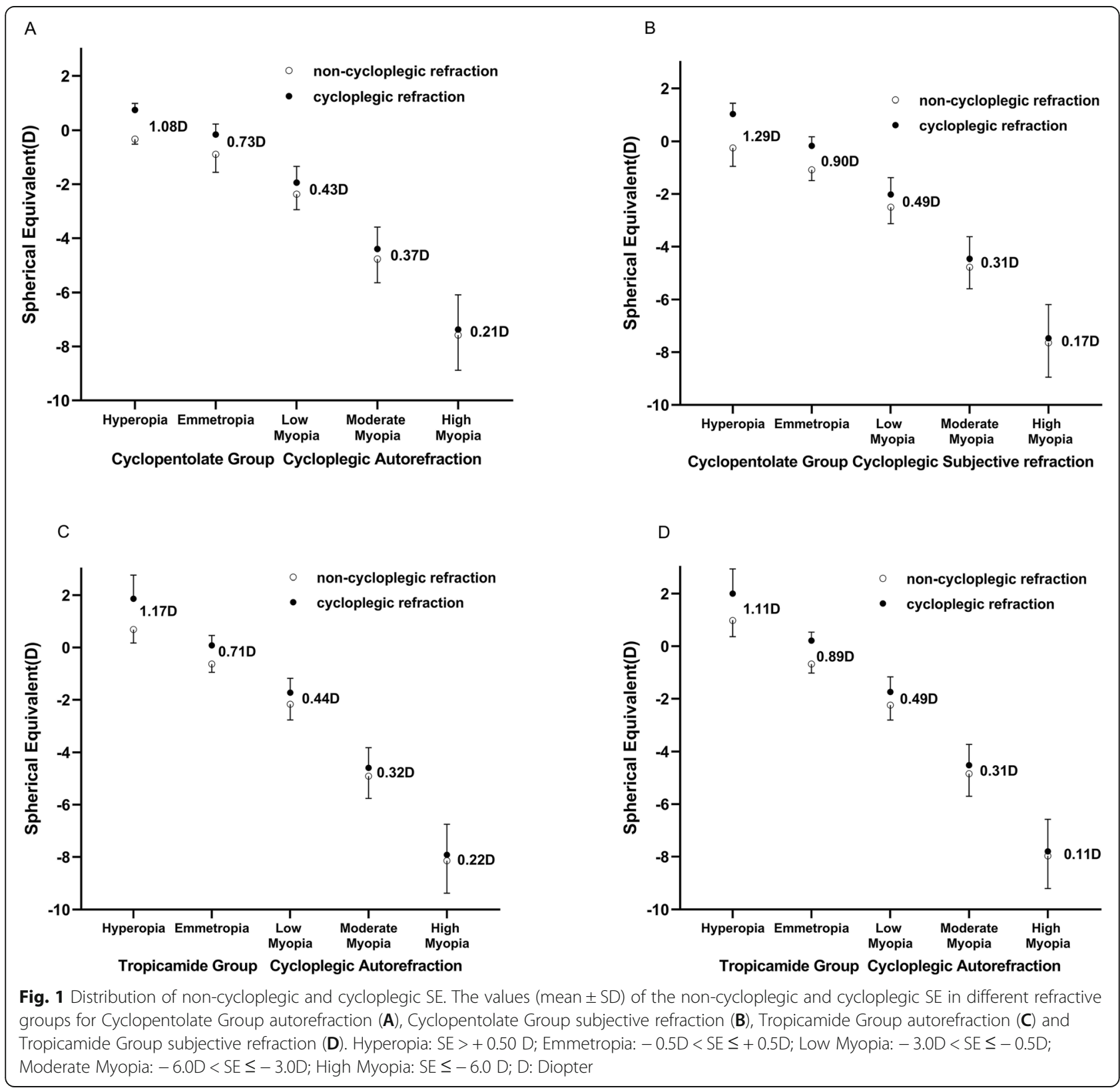




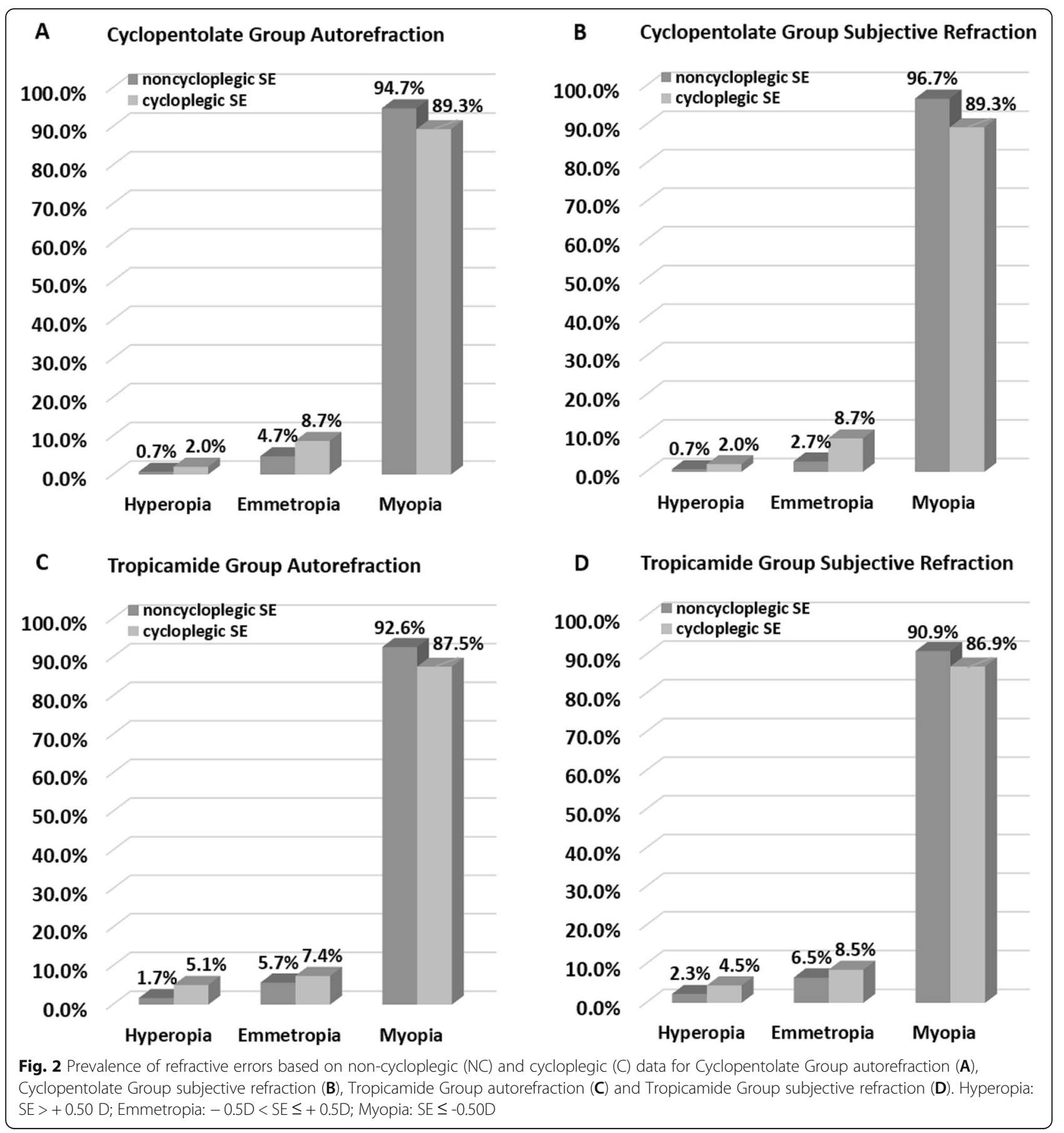

in tropicamide group, $p<0.05$ for all). It was speculated that accommodation capacity was stronger in hyperopes than in myopes. In the study of Sanfilippo, they reported that hyperopes aged 13 to 26 years tend to exhibit greater differences in refraction after cycloplegia than myopes [13]. The Tehran Eye Study [12] reported that in the $<25$ years age group, the difference in SE between cycloplegic and noncycloplegic refractive errors was higher for cycloplegic hyperopes (0.65D), than for cycloplegic emmetropes (0.30D), and cycloplegic myopes
(0.17D) $(p<0.001)$. The smallest difference in SE was for eyes with high myopia. The difference of SE value before and after cycloplegia was statistically significant in high myopes, with a mean value of $0.21 \mathrm{D}$ in cyclopentolate group and $0.22 \mathrm{D}$ in tropicamide group, which was of no clinical significance.

The findings of our study showed that there was no significant difference between autorefraction and subjective refraction with cycloplegia. In the cyclopentolate group, the mean difference in SE between autorefraction 
and subjective refraction after cycloplegia was $0.03 \mathrm{D}$ $(p>0.05)$. In the tropicamide group, the mean difference in SE between autorefraction and subjective refraction after cycloplegia was $0.06 \mathrm{D}(p>0.05)$. Choong et al [27] found that there was a tendency of over minus correction when the autorefractors were used under noncycloplegic conditions. No significant difference was found in mean SE between autorefraction and subjective refraction after cycloplegia. The Tehran Eye Study [28] reported that mean difference between cycloplegic autorefraction and subjective refraction was $0.62 \pm 0.54$ D $(p<0.001)$ for participants with a mean age of 31.7 years (range 5-95 years) and inter-method differences significantly decreased with age $(p<0.001)$. There are two factors that could explain the differences in results with our study. First, their study was conducted on participants with age range of 5-95 years, which has a wider age range than ours. Second, subjective refraction was measured under noncycloplegic condition which contributes to more negative or less positive than cycloplegic refraction. We suggested that autorefraction provides an alternative method used in place of subjective refraction in Chinese young adults under cycloplegic conditions in epidemiological studies of refractive errors.

Our study confirmed that cyclopentolate had no statistically significant superiority in cycloplegia efficacy compared with tropicamide. This result is consistent with several studies that compare cyclopentolate to tropicamide on the basis of refraction results [20-22]. In the study of 28 myopic adult refractive surgery patients (mean aged 35.4 years) in California [21], they reported that there is no statistically significant difference between tropicamide and cyclopentolate cycloplegic refractions. The study published in 1961 [22], demonstrated that cyclopentolate and tropicamide reduced accommodation to a similar level, but accommodation recovered much more quickly with tropicamide. Ihekaire et al [20] found that the cycloplegic effect of cyclopentolate was stronger than tropicamide in 25 Black young adults aged 17 to 29 years with dark irises. The epidemiological refraction examination of young adults requires a rapid, safe, effective method of obtaining accurate refractive errors. The cycloplegic effects of two cycloplegic agents were similar for Chinese young adults with dark irises. Because of rapid onset cycloplegic effect and shorter duration of peak effect, we suggested that tropicamide can be considered as a viable substitute for cyclopentolate in refraction study of Chinese young adults.

Our research had several limitations. We performed cycloplegic refraction until the pupils are fully dilated in our study. However, there are some studies that found that the time of maximum cycloplegia was earlier than that of maximum mydriasis $[18,29]$. Thus, the time of the cycloplegic refraction performed may also vary from study to study.

\section{Conclusions}

In conclusion, cycloplegic measurements were generally more positive or less negative than non-cycloplegic refractions. It is necessary to perform cycloplegia refraction for Chinese young adults with dark irises to obtain accurate refractive errors. We suggest that cycloplegic autorefraction using tropicamide may be considered as a reliable method for epidemiological studies of refraction in Chinese young adults with dark irises.

\section{Acknowledgements}

Not applicable.

\section{Authors' contributions}

YP and RHW conceived and supervised the experiment. BD and HMZ performed the study. HR, LQZ and BYW collected the data, and NJ analyzed the data. RXP and ZZL wrote the manuscript. YP and RHW contributed equally to this work and were both considered corresponding authors. RXP and ZZL contributed equally to this work and were both considered first authors. All authors read and approved the final manuscript.

\section{Funding}

This study was supported by grants from by the National Natural Science Foundation of China (No. 82070929). The funding organization had no role in the design or conduct of this research.

\section{Availability of data and materials}

Data and materials are available upon request from the corresponding author at rwei@tmu.edu.cn.

\section{Declarations}

Ethics approval and consent to participate

This study was approved by the Human Research Ethics Committee of Tianjin Medical University Eye Hospital and was conducted in accordance with the Declaration of Helsinki. Written informed consent was obtained from the participants before the data collection.

Consent for publication

We obtained written informed consent for publication from all the participants related to their personal or clinical details and images.

\section{Competing interests}

The authors declare that they have no competing interests.

Received: 4 November 2020 Accepted: 19 May 2021

Published online: 10 June 2021

\section{References}

1. Hopkins S, Sampson GP, Hendicott P, Lacherez P, Wood JM. Refraction in children: a comparison of two methods of accommodation control. Optom Vis Sci. 2012;89(12):1734-9. https://doi.org/10.1097/OPX.0b013e318277182c.

2. Fotedar R, Rochtchina E, Morgan I, Wang JJ, Mitchell P, Rose KA. Necessity of cycloplegia for assessing refractive error in 12-year-old children: a population-based study. Am J Ophthalmol. 2007;144(2):307-9. https://doi. org/10.1016/j.ajo.2007.03.041.

3. Zhao J, Mao J, Luo R, Li F, Pokharel GP, Ellwein LB. Accuracy of noncycloplegic autorefraction in school-age children in China. Optom Vis Sci. 2004;81(1):49-55. https://doi.org/10.1097/00006324-200401000-00010.

4. Zhu D, Wang Y, Yang $X$, Yang D, Guo K, Guo Y, et al. Pre- and Postcycloplegic refractions in children and adolescents. PLoS One. 2016; 11(12):e0167628. https://doi.org/10.1371/journal.pone.0167628. 
5. Morgan IG, Iribarren R, Fotouhi A, Grzybowski A. Cycloplegic refraction is the gold standard for epidemiological studies. Acta Ophthalmol. 2015;93(6):5815. https://doi.org/10.1111/aos.12642.

6. Wu JF, Bi HS, Wang SM, Hu YY, Wu H, Sun W, et al. Refractive error, visual acuity and causes of vision loss in children in Shandong, China. The Shandong Children Eye Study. PLoS One. 2013;8(12):e82763.

7. Wolffsohn JS, Kollbaum PS, Berntsen DA, Atchison DA, Benavente A, Bradley A, et al. IMI - clinical myopia control trials and instrumentation report. Invest Ophthalmol Vis Sci. 2019;60(3):M132-M60. https://doi.org/10.1167/iovs.18-2 5955.

8. Hu YY, Wu JF, Lu TL, Wu H, Sun W, Wang XR, et al. Effect of cycloplegia on the refractive status of children: the Shandong children eye study. PLOS One. 2015;10(2):e0117482. https://doi.org/10.1371/journal.pone.0117482.

9. Sun YY, Wei SF, Li SM, Hu JP, Yang XH, Cao K, et al. Cycloplegic refraction by $1 \%$ cyclopentolate in young adults: is it the gold standard? The Anyang University students eye study (AUSES). Br J Ophthalmol. 2018;103(5):654-8.

10. Mimouni M, Zoller L, Horowitz J, Wygnanski-Jaffe T, Morad Y, Mezer E. Cycloplegic autorefraction in young adults: is it mandatory? Graefes Arch Clin Exp Ophthalmol. 2016;254(2):395-8. https://doi.org/10.1007/s00417-01 5-3246-1.

11. Krantz EM, Cruickshanks KJ, Klein BE, Klein R, Huang GH, Nieto FJ. Measuring refraction in adults in epidemiological studies. Arch Ophthalmol. 2010; 128(1):88-92. https://doi.org/10.1001/archophthalmol.2009.349.

12. Fotouhi A, Morgan IG, Iribarren R, Khabazkhoob M, Hashemi H. Validity of noncycloplegic refraction in the assessment of refractive errors: the Tehran eye study. Acta Ophthalmol. 2012;90(4):380-6. https://doi.org/10.1111/j.1 755-3768.2010.01983.x

13. Sanfilippo PG, Chu BS, Bigault O, Kearns LS, Boon MY, Young TL, et al. What is the appropriate age cut-off for cycloplegia in refraction? Acta Ophthalmol. 2014;92(6):e458-62. https://doi.org/10.1111/aos.12388.

14. Fan DS, Rao SK, Ng JS, Yu CB, Lam DS. Comparative study on the safety and efficacy of different cycloplegic agents in children with darkly pigmented irides. Clin Exp Ophthalmol. 2004;32(5):462-7. https://doi.org/10.1111/j.14429071.2004.00863.x

15. Mutti DO, Zadnik K, Egashira S, Kish L, Twelker JD, Adams AJ. The effect of cycloplegia on measurement of the ocular components. Invest Ophthalmol Vis Sci. 1994;35(2):515-27.

16. Chen ZJ. Clinical ophthalmological pharmacology. Beijing: Chemical Industry Press; 2002.

17. Farhood QK. Cycloplegic Refraction in Children with Cyclopentolate versus Atropine. J Clin Exp Ophthalmol. 2012;03(07):1-6.

18. Manny RE, Fern KD, Zervas HJ, Cline GE, Scott SK, White JM, et al. 1\% Cyclopentolate hydrochloride: another look at the time course of cycloplegia using an objective measure of the accommodative response. Optom Vis Sci. 1993;70(8):651-65. https://doi.org/10.1097/00006324-1993 08000-00013.

19. Yazdani N, Sadeghi R, Momeni-Moghaddam H, Zarifmahmoudi L, Ehsaei A. Comparison of cyclopentolate versus tropicamide cycloplegia: a systematic review and meta-analysis. J Optom. 2018;11(3):135-43. https://doi.org/10.101 6/j.optom.2017.09.001

20. Ihekaire DE. The comparative efficacy of Cyclopegic drugs-Tropicamide and Cyclopentolate on school children. Int J Sci Res Educ. 2012;5(3):223-46.

21. Hofmeister EM, Kaupp SE, Schallhorn SC. Comparison of tropicamide and cyclopentolate for cycloplegic refractions in myopic adult refractive surgery patients. J Cataract Refract Surg. 2005;31(4):694-700. https://doi.org/10.1016/ j.jcrs.2004.10.068

22. Gettes BC, Belmont O. Tropicamide: comparative cycloplegic effects. Arch Ophthalmol. 1961;66(3):336-40. https://doi.org/10.1001/archopht.1961. 00960010338007.

23. Salazar M, Shimada K, Patil PN. Iris pigmentation and atropine mydriasis. J Pharmacol Exp Ther. 1976;197(1):79-88.

24. Emiru VP. Response to mydriatics in the African. Br J Ophthalmol. 1971;55(8): 538-43. https://doi.org/10.1136/bjo.55.8.538

25. van Minderhout HM, Joosse MV, Grootendorst DC, Schalij-Delfos NE. A randomized clinical trial using atropine, cyclopentolate, and tropicamide to compare refractive outcome in hypermetropic children with a dark iris; skin pigmentation and crying as significant factors for hypermetropic outcome. Strabismus. 2019;27(3):127-38. https://doi.org/10.1080/09273972.2019.1629466.

26. Jorge J, Queiros A, Gonzalez-Meijome J, Fernandes P, Almeida JB, Parafita MA. The influence of cycloplegia in objective refraction. Ophthal Physiol Opt. 2005;25:340-5.
27. Choong YF, Chen AH, Goh PP. A comparison of autorefraction and subjective refraction with and without cycloplegia in primary school children. Am J Ophthalmol. 2006;142(1):68-74. https://doi.org/10.1016/j.ajo.2 006.01 .084

28. Hashemi H, Khabazkhoob M, Asharlous A, Soroush S, Yekta A, Dadbin N, et al. Cycloplegic autorefraction versus subjective refraction: the Tehran eye study. Br J Ophthalmol. 2016;100(8):1122-7. https://doi.org/10.1136/ bjophthalmol-2015-307871.

29. Laojaroenwanit S, Layanun V, Praneeprachachon P, Pukrushpan P. Time of maximum cycloplegia after instillation of cyclopentolate $1 \%$ in children with brown irises. Clin Ophthalmol. 2016;10:897-902. https://doi.org/10.2147/ OPTH.S102611.

\section{Publisher's Note}

Springer Nature remains neutral with regard to jurisdictional claims in published maps and institutional affiliations.
Ready to submit your research? Choose BMC and benefit from:

- fast, convenient online submission

- thorough peer review by experienced researchers in your field

- rapid publication on acceptance

- support for research data, including large and complex data types

- gold Open Access which fosters wider collaboration and increased citations

- maximum visibility for your research: over $100 \mathrm{M}$ website views per year

At $\mathrm{BMC}$, research is always in progress.

Learn more biomedcentral.com/submissions 